\title{
Assessment of effective radiated power of the partial discharge emulator source.
}

\author{
JABER, A., LAZARIDIS, P., SAEED, B., ZHANG, Y., KHAN, U., UPTON, D., \\ AHMED, H., MATHER, P., ATKINSON, R., JUDD, M., VIEIRA, M.F.Q. and \\ GLOVER, I.
}

The final authenticated version is available online at: https://doi.org/10.1007/978-3-319-53850-1 12. This pre-copyedited version is made available under the Springer terms of reuse for AAMs:

https://www.springer.com/gp/open-access/publication-policies/aam-terms-of-use 


\title{
Assessment of Effective Radiated Power of the Partial Discharge Emulator Source
}

\author{
Adel Jaber ${ }^{1}$, Pavlos Lazaridis ${ }^{1}$, Bahghtar Saeed ${ }^{1}$, Yong Zhang ${ }^{1}$, Umar Khan ${ }^{1}$, \\ David Upton ${ }^{1}$, Hamd Ahmed ${ }^{1}$, Peter Mather ${ }^{1}$, Robert Atkinson ${ }^{2}$, Martin Judd ${ }^{3}$, Maria \\ Fatima Queiroz Vieira ${ }^{4}$ and Ian Glover ${ }^{1}$ \\ ${ }^{1}$ Department of Engineering \& Technology, University of Huddersfield, Huddersfield HD1 \\ $3 \mathrm{DH}, \mathrm{UK}$ \\ ${ }^{2}$ Deptartment of Electronic and Electrical Engineering, University of Strathclyde, Glasgow \\ G1 1XW, UK \\ ${ }^{3}$ High Frequency Diagnostics and Engineering Ltd, Glasgow G3 7JT, UK \\ ${ }^{4}$ Department of Electrical Engineering, Universidade Federal de Campina, Campina Grande, \\ Brazil \\ E-mail: Adel.Jaber@hud.ac.uk
}

\begin{abstract}
Two effective partial discharge (PD) measurement techniques are used; a galvanic contact measurement technique similar to the IEC 60270 standard measurement and free-space radiometric (FSR) measurement. Several types of PD sources are specially constructed: two internal PD emulators and an emulator of the floating-electrode type. An AC power supply is applied to the $\mathrm{PD}$ source and the radiated signal is captured using a wideband biconical antenna. The calibration of PD sources is demonstrated. Effective radiated power (ERP) of the PD sources using a PD calibration device is determined.
\end{abstract}

Keywords: Absolute partial discharge intensity; Effective radiated power; free space radiometric measurement; galvanic contact measurement.

\section{Introduction}

Measurement of PD activity can be used to diagnose substation insulation faults and predict the catastrophic failure of high voltage (HV) equipment. Free-space radiometric measurement has been proposed as a particularly convenient technique for PD source location and monitoring, at least in part, because it requires no physical connection to electrical components. The FSR technique uses remotely located antennas to receive the radio frequency (RF) signal radiated by transient PD pulses [1], [2]. Traditionally, it has been the temporal evolution of FSR-derived data that has been used to flag PD of immediate engineering concern since the absolute PD intensity (in $\mathrm{pC}$ ) has been thought impractical to assess. Here, we report work in progress which targets to link FSR PD data to absolute PD intensity. 


\section{Apparatus}

The apparatus used to simultaneously capture galvanic contact, and FSR PD measurements is shown in Fig. 1. More information about PD measurements can be found in [3], [4], [5] and [6].

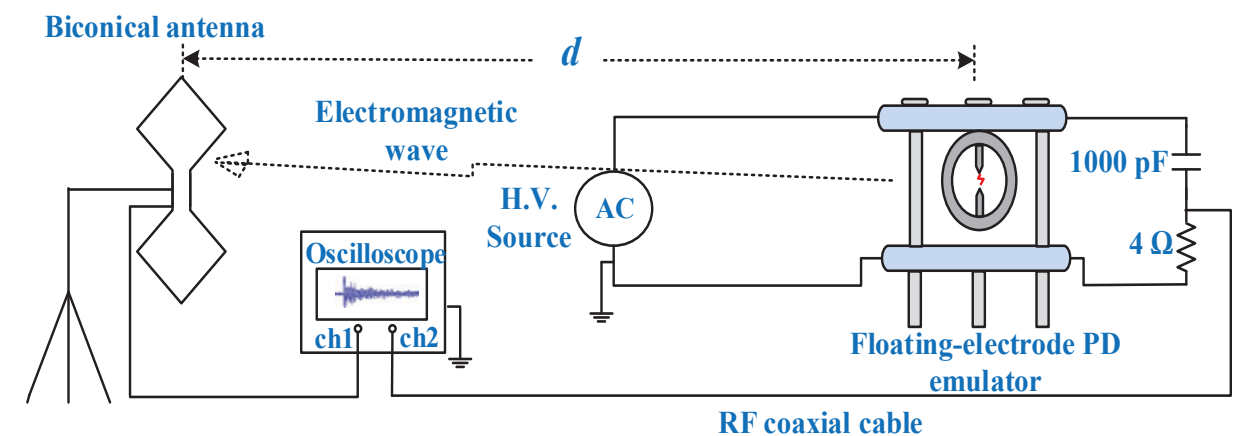

Fig. 1. Measurement apparatus.

PD is generated by applying an AC HV to the PD source. Three PD emulators have been constructed. An emulator of the floating-electrode type, an acrylic tube internal emulator (PD discharge in the air and in the oil) and an epoxy dielectric internal PD emulator, that are shown in Fig. 2. The voltage rating of the $1 \mathrm{nF}$ coupling capacitor (shown in Fig. 1) used to make the galvanic PD measurements is $40 \mathrm{kV}$. When the electric field is sufficiently large, PD occurs across the electrode gaps. More details about PD sources can be found in [7], [8], [9] and [10].

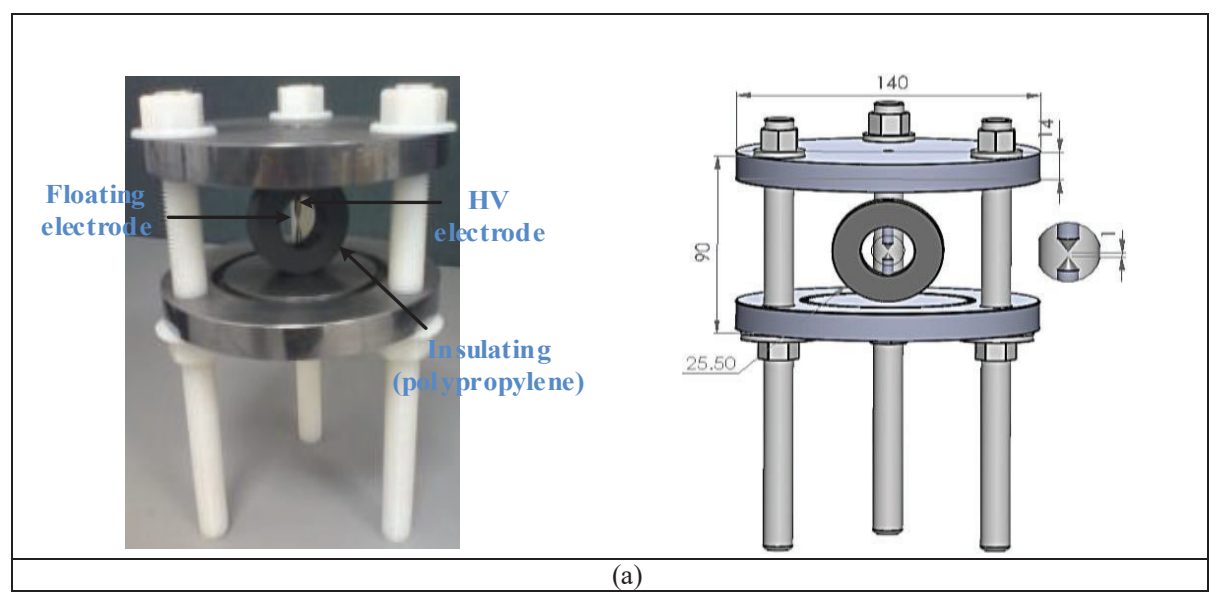




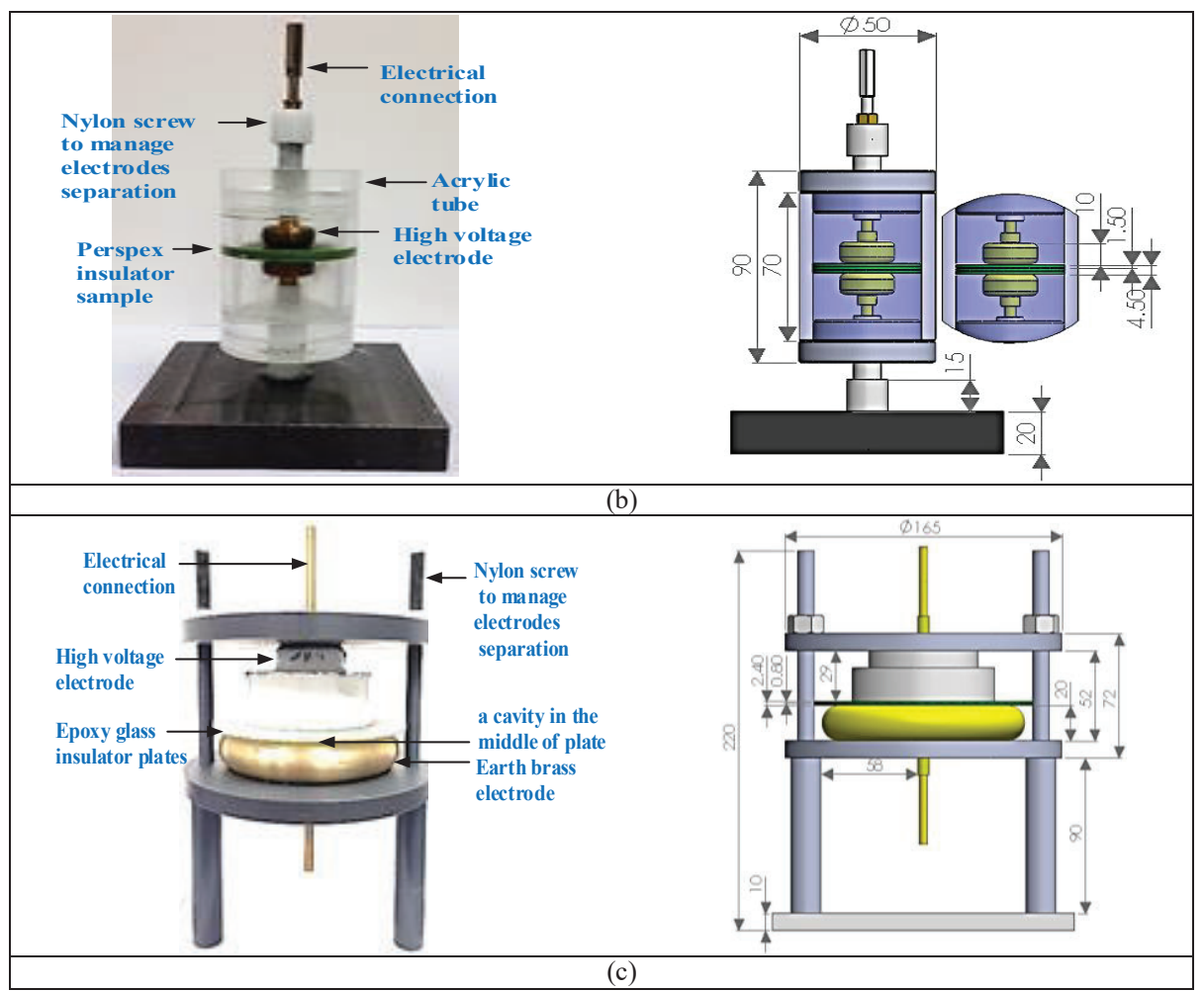

Fig. 2. (a) Floating electrode PD emulator (b) Acrylic tube internal PD emulator and (c) Epoxy dielectric internal PD emulator (dimensions in $\mathrm{mm}$ ).

The radiometric measurements were made using a wideband biconical antenna connected to a $4 \mathrm{GHz}, 20 \mathrm{GSa} / \mathrm{s}$, digital sampling oscilloscope (DSO). The antenna was vertically polarised. The frequency range of the antenna is $20 \mathrm{MHz}$ to $1 \mathrm{GHz}$ and its nominal impedance is $50 \mathrm{ohms}$. The antenna gain at $100 \mathrm{MHz}$ is around $-9 \mathrm{dBi}$ and its dimensions are $540 \mathrm{~mm} \times 225 \mathrm{~mm} \times 225 \mathrm{~mm}$. A commercial PD calibration device has been used to assess the effective radiated power of the emulator as a function of PD apparent charge. The off-line HVPD $\mathrm{pC}$ calibrator is designed to provide a range of current pulses of specified charge from $1 \mathrm{pC}$ up to $100 \mathrm{nC}$ [11].

\section{Example Event}

Example FSR and galvanic contact measurements for the same PD event are compared in Fig. 3(a). The PD source used for the comparison in this paper is a floating electrode PD emulator. The voltage at which this PD event occurred was $6.2 \mathrm{kV}$. The frequency spectra, obtained using an FFT, are compared in Fig. 3(b). 


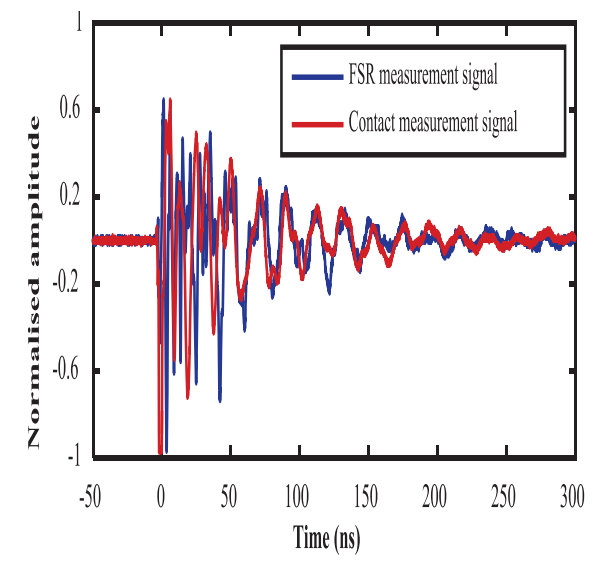

Fig. 3. (a) PD normalised time-series.

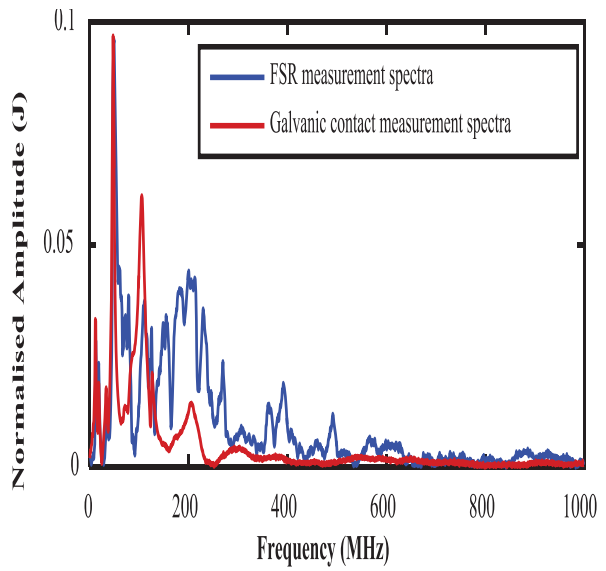

(b) PD spectra.

\section{PD Sources Calibration}

The oscillatory nature of the PD time-series makes assessing apparent charge nontrivial, even in a galvanic measurement. The example of experimental setup measuring circuit in Fig. 4 was used for calibrating PD sources. The artificial PD sources have therefore been calibrated by injecting a narrow calibration pulse of known charge. The calibration pulse emulates a PD event of a particular (known) intensity. A typical observed waveform is shown in Fig. 5. The measured charge has been estimated by integrating the first half-cycle of the PD source time-series current.

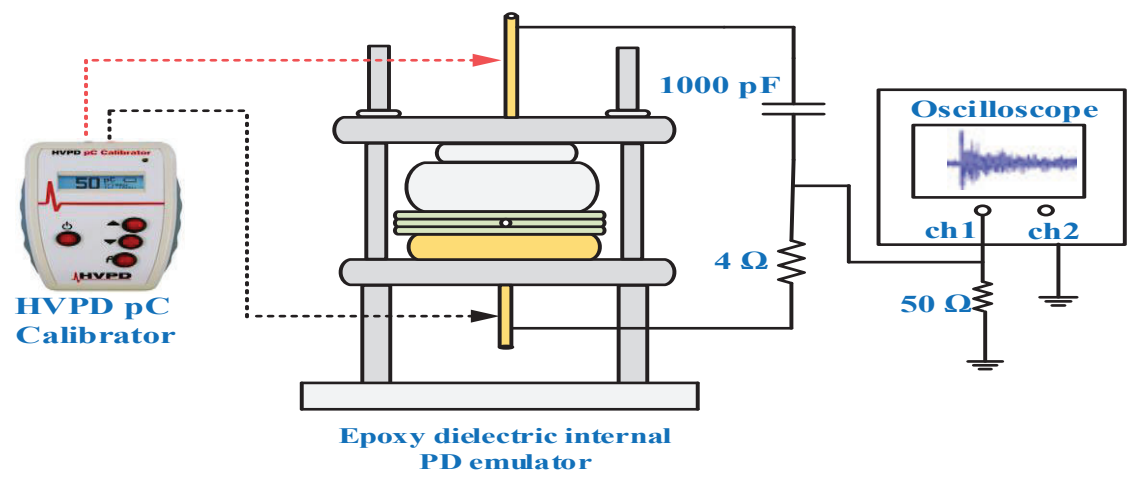

Fig. 4. PD source calibration. 


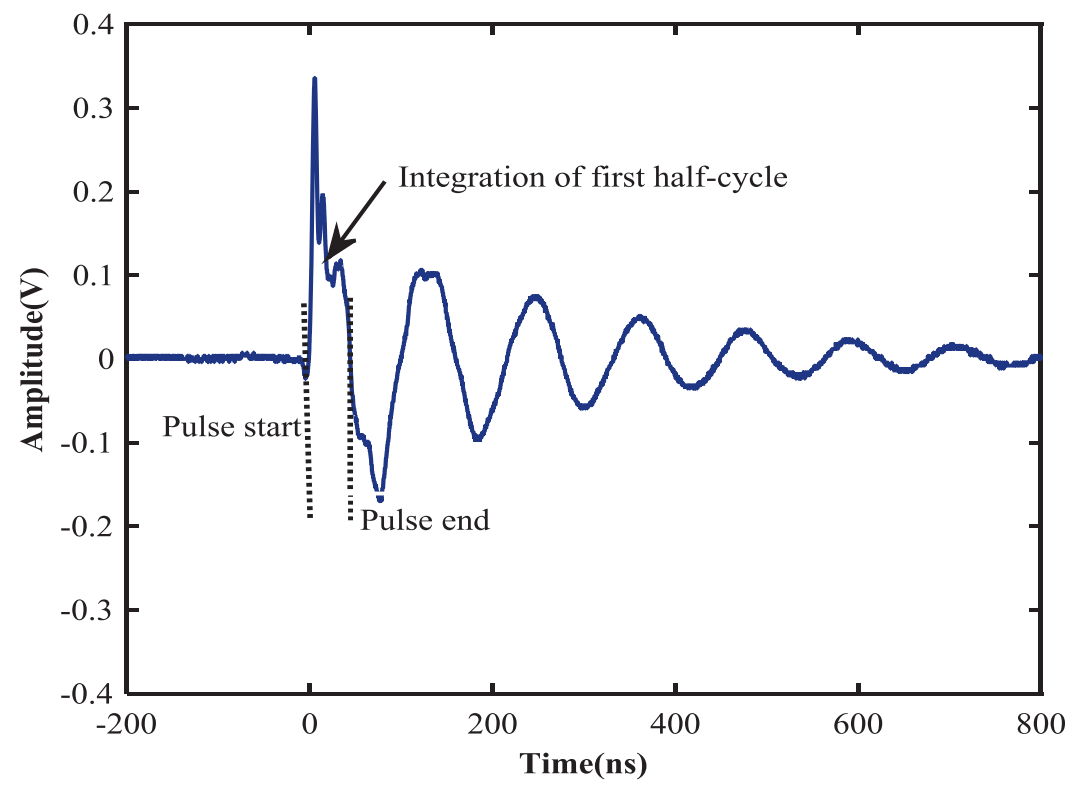

Fig. 5. Example of current waveform for an injected charge of $1 \mathrm{nC}$.

Fig. 6 shows the charge calculated from the galvanic contact measurement against the specification of the charge injection device.

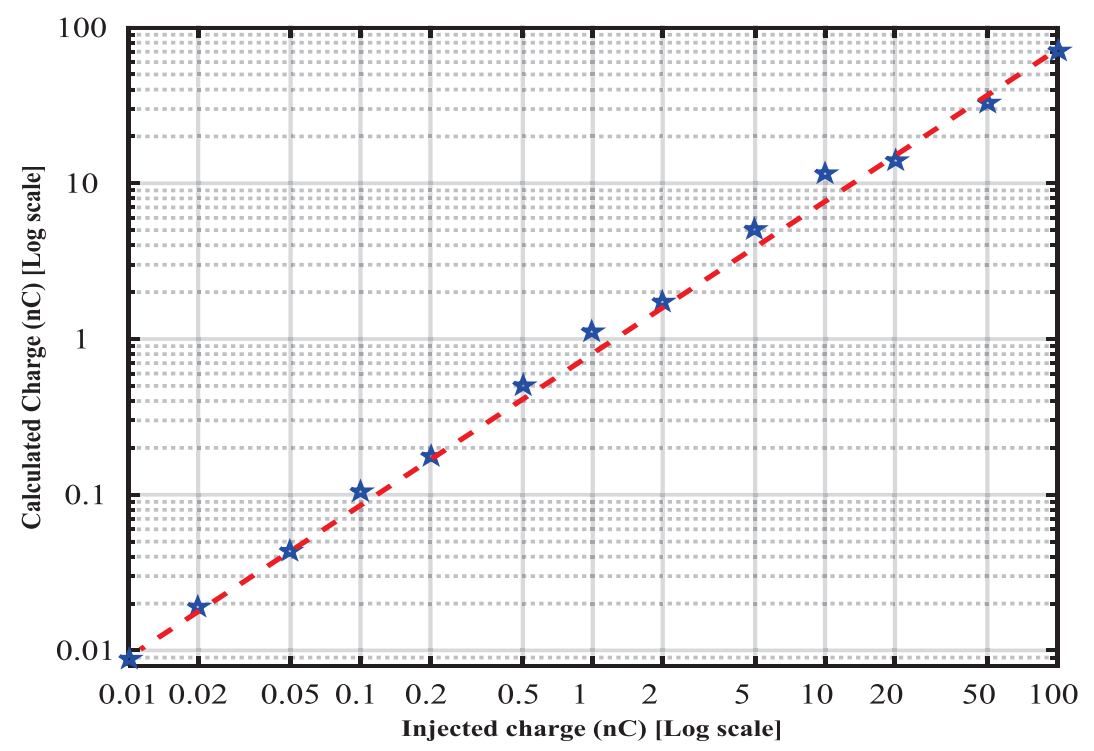

Fig. 6. Measured charge versus specified charge of charge injection device. 
Regarding the Free-Space radiometric measurements, different distances were used in measurement system shown in Fig. 1 between the three PD emulators and the biconical antenna. Fig. 7 shows an example of the variation with distance of received peak voltage, received field-strength and apparent effective radiated power. The radiated signal amplitude is decreasing by increasing the distance between the PD source and the biconical antenna, due to radiation losses. In free-space, and in the farfield, apparent ERP would be independent of source-antenna range. The variation observed may be due to near-field and/or multipath effects. This is under investigation. The relationship between calculated charge and average ERP for different PD emulator source types is presented in Table 1. The ERP of the PD source emulator is estimated from the received electric field strength according to the formula for free space propagation formula (1) as follows:

$$
E(d B \mu V / m)=107+E R P(d B m)-20 \log _{10} d(m)
$$

where: $\mathrm{E}$ is the electric field strength, ERP is the effective radiated power and $\mathrm{d}$ is the PD source distance from the receiving antenna.

Table 1. Relationship between calculated charge and effective radiated power of PD sources.

\begin{tabular}{ccccc}
\hline & $\begin{array}{c}\text { Floating- } \\
\text { electrode } \\
\text { PD source }\end{array}$ & $\begin{array}{c}\text { Acrylic tube } \\
\text { internal PD } \\
\text { source without } \\
\text { oil filling }\end{array}$ & $\begin{array}{c}\text { Acrylic tube } \\
\text { internal PD } \\
\text { source with oil } \\
\text { filling }\end{array}$ & $\begin{array}{c}\text { Epoxy } \\
\text { dielectric } \\
\text { internal PD } \\
\text { source }\end{array}$ \\
\hline $\begin{array}{c}\text { Calculated } \\
\text { charge }(\mathrm{nC})\end{array}$ & 5.3 & 3.8 & 2.1 & 0.9 \\
$\begin{array}{c}\text { Average peak } \\
\text { ERP }(\mathrm{dBm})\end{array}$ & 25 & 12 & 7 & 1.4 \\
\hline
\end{tabular}

Fig. 8 relates ERP (estimated from radiometric measurements) and absolute PD intensity (estimated from galvanic measurement of the PD current transient). The convincing nature of this relationship suggests a useful estimate of absolute PD intensity from a remote measurement of PD radiation is possible. 

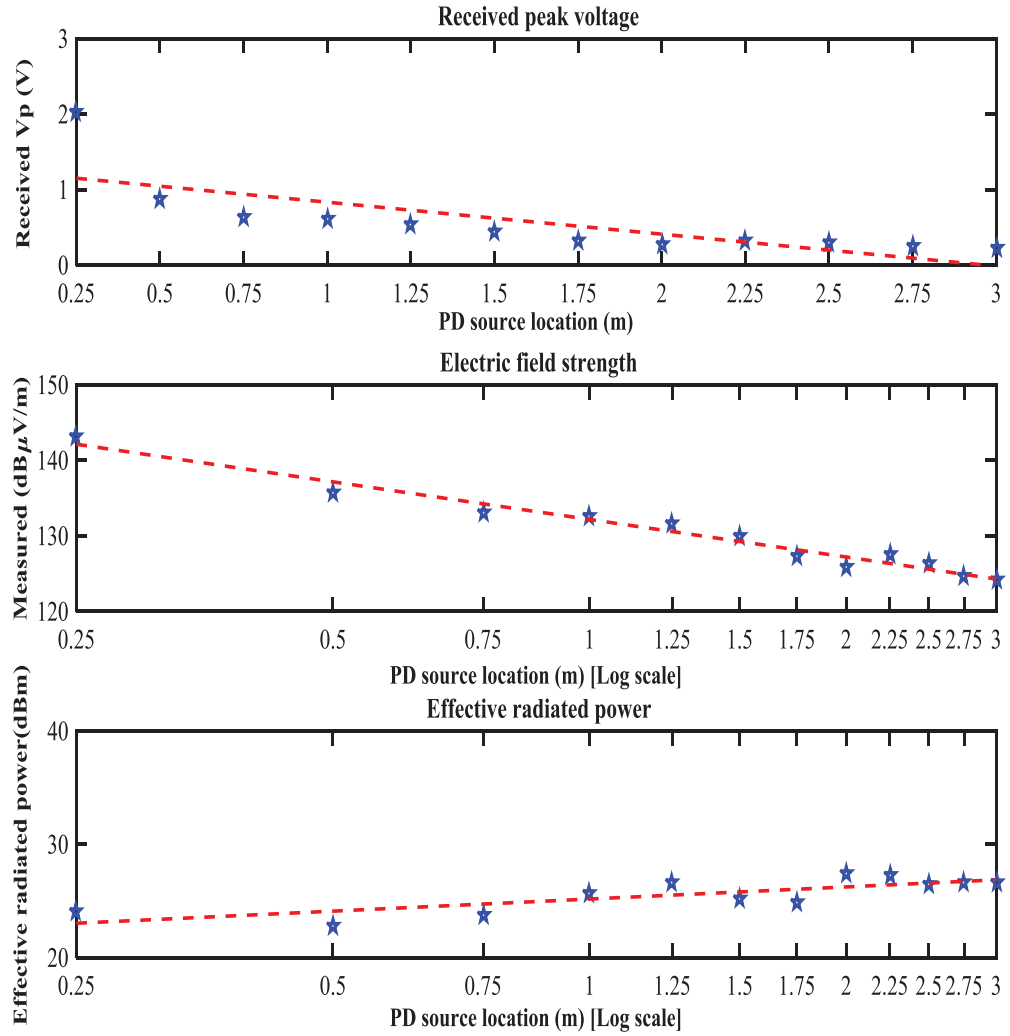

Fig. 7. (a) Received peak voltage, (b) Electric field strength and (c) ERP as a function of PD source-antenna range.

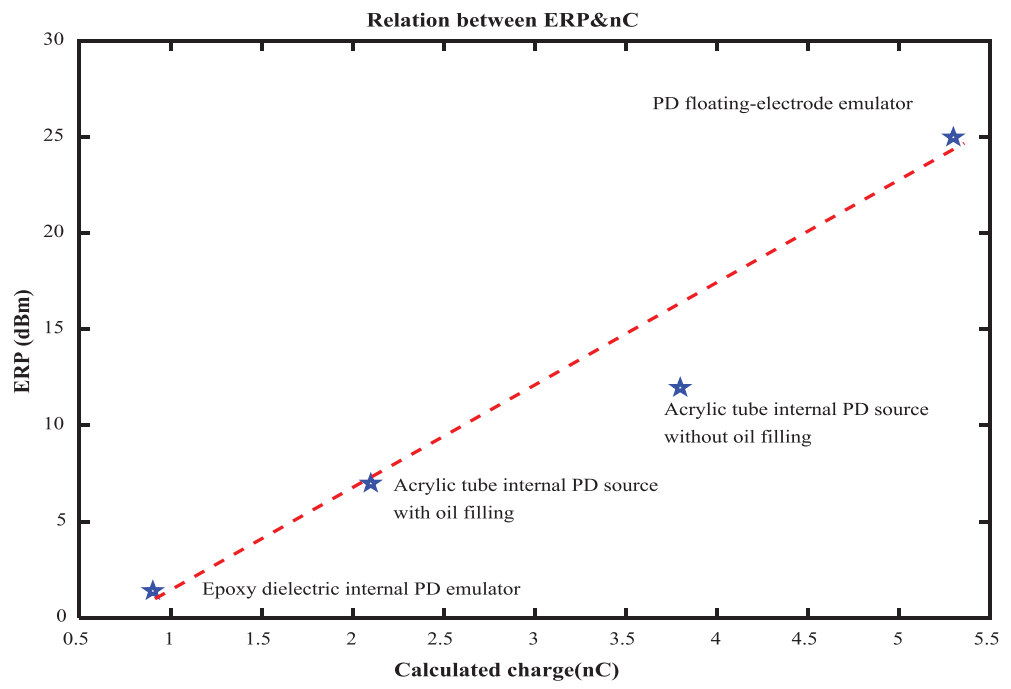

Fig. 8. Determined ERP of different types of PD sources versus calculated charge. 


\section{Conclusions}

Estimated charge, peak voltage amplitude and effective radiated power of FSR measurements against the location of the PD emulator are used for the calibration of PD sources. By using the proposed method an apparent charge in picocoulombs can be inferred for a PD source from FSR measurements.

Acknowledgments. The authors acknowledge the Engineering and Physical Sciences Research Council for their support of this work under grant EP/J015873/1.

\section{References}

1. Zhang, Y., Upton, D., Jaber, A., Ahmed, H., Saeed, B., Mather, P., Lazaridis, P. Mopty, A., Tachtatzis, C., Atkinson, R., Judd, M., Vieira, M. F. Q., and Glover, I. A.: Radiometric wireless sensor network monitoring of partial discharge sources in electrical substations. Hindawi International Journal of Distributed Sensor Networks, vol. 2015, p. 179, (2015).

2. Neto, J. M., Y., Upton, D., Jaber, A., Ahmed, H., Saeed, B., Mather, Tachtatzis, C., Atkinson, R., Judd, M., Vieira, M. F. Q., and Glover, I. A.: Radiometric location of partial discharge sources for the future smart grid. In: General Assembly and Scientific Symposium (URSI GASS), XXXIth URSI, pp. 1--4. Beijing, (2014).

3. Jaber, A., Lazaridis, P., Saeed, B., Zhang, Y., Khan, U., Upton, D., A., Ahmed, H., Mather, P., Vieira, M. F. Q., Atkinson, R., Judd, M., Seviour, R. and Glover, I. A.: Frequency Spectrum Analysis of Radiated Partial Discharge Signals. IET EUROEM 2016 conference (European Electromagnetics Symposium), pp. 1--2. London (2016).

4. Reid, A.J., Judd, M.D., Fouracre, R.A., Stewart, B.G. and Hepburn, D.M.,: Simultaneous measurement of partial discharges using IEC60270 and radio-frequency techniques. Dielectrics and Electrical Insulation, IEEE Transactions on, vol. 18, pp. 444-455, (2011).

5. Jaber, A., Lazaridis, P., Saeed, B., Zhang, Y., Khan, U., Upton, D., A., Ahmed, H., Mather, P., Vieira, M. F. Q., Atkinson, R., Judd, M. and Glover, I. A.: Comparative study of Partial Discharge Emulators for the Calibration of Free-Space Radiometric Measurements. 22nd IEEE International Conference on Automation and Computing (ICAC'16), pp. 1--4. Colchester (2016).

6. Jaber, A., Lazaridis, P., Saeed, B., Zhang, Y., Khan, U., Upton, D., A., Ahmed, H., Mather, P., Vieira, M. F. Q., Atkinson, R., Judd, M. and Glover, I. A.: Comparison of contact measurement and free-space radiation measurement of partial discharge signals. In: Automation and Computing (ICAC), 2015 21st International Conference, pp. 1--4. IEEE Press, Glasgow (2015).

7. Jaber, A., Lazaridis, P., Saeed, B., Zhang, Y., Khan, U., Upton, D., A., Ahmed, H., Mather, P., Vieira, M. F. Q., Atkinson, R., Judd, M. and Glover, I. A.: Validation of Partial Discharge Emulators Simulation using Free-Space Radiometric Measurements. In: International Conference for Students on Applied Engineering (ICSAE 2016), pp. 1--4. Newcastle (2016).

8. Hampton, B. F.: UHF diagnostics for gas insulated substations. on High Voltage Engineering. Eleventh International Symposium on (Conf. Publ. No. 467), pp. 6--16. London (1999).

9. de Souza Neto, J.M.R., de Macedo, E.C.T., da Rocha Neto, J.S., Da Costa, E.G., Bhatti, S.A. and Glover, I.A.: Partial Discharge Location using Unsynchronized Radiometer Network for 
Condition Monitoring in HV Substations-A Proposed Approach. Journal of Physics: Conference Series, p. 012053 (2012).

10. Niasar, M.G., Taylor, N., Janus, P., Wang, X., Edin, H. and Kiiza, R.C.: Partial discharges in a cavity embedded in oil-impregnated paper: effect of electrical and thermal aging. IEEE Transactions on Dielectrics and Electrical Insulation, vol. 22, pp. 1071--1079 (2015). 11. HVPD. Available: http://www.hvpd.co.uk 